\title{
Tumor-Specific Reactive Oxygen Species Accelerators Improve Chimeric Antigen Receptor T Cell Therapy in B Cell Malignancies
}

\author{
Hyeon Joo Yoo ${ }^{1}$, Yibin Liu ${ }^{1}$, Lei Wang ${ }^{1}$, Maria-Luisa Schubert ${ }^{1}$, Jean-Marc Hoffmann ${ }^{1}$, \\ Sanmei Wang ${ }^{1}$, Brigitte Neuber ${ }^{1}$, Angela Hückelhoven-Krauss ${ }^{1}$, Ulrike Gern ${ }^{1}$, Anita Schmitt ${ }^{1}$, \\ Carsten Müller-Tidow ${ }^{1,2}$, Peter Dreger ${ }^{1,2}$, Andriy Mokhir ${ }^{3}$, Michael Schmitt ${ }^{1,2}$ and \\ Leopold Sellner $1,2, *$ (D) \\ 1 Department of Internal Medicine V, Heidelberg University Hospital, 69120 Heidelberg, Germany; \\ hyeonjoo_7@hotmail.com (H.J.Y.); Yibin.Liu@med.uni-heidelberg.de (Y.L.); \\ Lei.Wang@med.uni-heidelberg.de (L.W.); Maria-Luisa.Schubert@med.uni-heidelberg.de (M.-L.S.); \\ Jean-Marc.Hoffmann@med.uni-heidelberg.de (J.-M.H.); Sanmei.Wang@med.uni-heidelberg.de (S.W.); \\ Brigitte.Neuber@med.uni-heidelberg.de (B.N.); Angela.Hueckelhoven-Krauss@med.uni-heidelberg.de (A.H.-K.); \\ Ulrike.Gern@med.uni-heidelberg.de (U.G.); Anita.Schmitt@med.uni-heidelberg.de (A.S.); \\ Carsten.Mueller-Tidow@med.uni-heidelberg.de (C.M.-T.); Peter.Dreger@med.uni-heidelberg.de (P.D.); \\ michael.schmitt@med.uni-heidelberg.de (M.S.) \\ 2 National Center for Tumor Diseases (NCT), German Cancer Consortium (DKTK), \\ 69120 Heidelberg, Germany \\ 3 Organic Chemistry II, Department Chemistry and Pharmacy, Friedrich-Alexander-University of \\ Erlangen-Nürnberg, 91058 Erlangen, Germany; andriy.mokhir@fau.de \\ * Correspondence: leopold.sellner@med.uni-heidelberg.de
}

Received: 17 April 2019; Accepted: 16 May 2019; Published: 18 May 2019

\begin{abstract}
Chimeric antigen receptor T cell (CART) therapy is currently one of the most promising treatment approaches in cancer immunotherapy. However, the immunosuppressive nature of the tumor microenvironment, in particular increased reactive oxygen species (ROS) levels, provides considerable limitations. In this study, we aimed to exploit increased ROS levels in the tumor microenvironment with prodrugs of ROS accelerators, which are specifically activated in cancer cells. Upon activation, ROS accelerators induce further generation of ROS. This leads to an accumulation of ROS in tumor cells. We hypothesized that the latter cells will be more susceptible to CARTs. CD19-specific CARTs were generated with a CD19.CAR.CD28.CD137zeta third-generation retroviral vector. Cytotoxicity was determined by chromium-51 release assay. Influence of the ROS accelerators on viability and phenotype of CARTs was determined by flow cytometry. The combination of CARTs with the ROS accelerator PipFcB significantly increased their cytotoxicity in the Burkitt lymphoma cell lines Raji and Daudi, as well as primary chronic lymphocytic leukemia cells. Exposure of CARTs to PipFcB for $48 \mathrm{~h}$ did not influence T cell exhaustion, viability, or T cell subpopulations. In summary, the combination of CARTs with ROS accelerators may improve adoptive immunotherapy and help to overcome tumor microenvironment-mediated treatment resistance.
\end{abstract}

Keywords: chimeric antigen receptor; CAR; CART; immunotherapy; reactive oxygen species; ROS; chronic lymphocytic leukemia; CLL; aminoferrocene

\section{Introduction}

CD19-specific chimeric antigen receptor T cell (CART) therapy is currently one of the most outstanding cellular immunotherapy approaches, achieving substantial clinical benefit for patients 
with relapsed B-cell malignancies [1]. However, despite remarkable results, primary and secondary resistances occur. Escape mechanisms include down-regulation of tumor antigens [2], alterations of target antigens by alternative splicing [3], activation of alternative signaling pathways, and overexpression of inhibitory signals (e.g., cytotoxic T-lymphocyte-associated antigen 4 (CTLA4) or programmed cell death-1 (PD1)) [4]. Enhancing efficacy of CART therapy using combination strategies may be necessary to overcome resistance and achieve long-lasting remissions.

Cancer therapy against only a single target may facilitate the development of resistances. The combination with targeted drugs or immunomodulatory compounds may be a promising approach to improve clinical efficacy of CARTs. Previous studies reported that the addition of ibrutinib or lenalidomide to CART cells can improve effector functions in vitro, as well as tumor control in vivo [5-7]. Therefore, CART combination therapy approaches are a major focus of research efforts and may overcome treatment resistance towards adoptive immunotherapy.

The tumor microenvironment plays an important role in immune escape and tumor cell survival $[8,9]$. Therefore, it is of great interest to develop strategies to exploit these cancer-specific alterations by targeted combination therapies [10]. Metabolic alterations such as enhanced levels of oxidative stress and reactive oxygen species (ROS) are hallmarks of cancer [11]. Increased ROS levels have been demonstrated to be responsible for immune escape of cancer cells [12,13]. This crucial aspect of ROS-enrichment in the tumor microenvironment was exploited to design specific ROS accelerators for cancer treatment. They are activated in the presence of high ROS levels, and subsequently trigger further ROS production. This results in specific cell death of cancer cells [14-16]. Several such prodrugs have been reported. Organochalcogenide-based prodrugs can catalyze the oxidation of glutathione (GSH) to glutathione disulfide (GSSG) in the presence of $\mathrm{H}_{2} \mathrm{O}_{2}$ [17]. Furthermore, $\mathrm{N}$-alkylaminoferrocene-based prodrugs are converted into ROS amplifiers (electron rich ferrocene) and alkylating agents (quinone methide). Both metabolites induce oxidative stress and lead to cancer cell death [14-16]. In previous studies, $N$-alkylaminoferrocene-based prodrugs demonstrated selective killing of primary chronic lymphocytic leukemia (CLL) cells, compared to healthy peripheral blood mononuclear cells (PBMCs) [14-16].

In this study, we focused on the N-alkylaminoferrocene-based ROS accelerator $\mathrm{N}$-(3-(piperidin1-ylmethyl)benzyl)-4-(ferrocenylcarbamatmethyl)phenyl boronic acid pinacol ester (PipFcB) as a tumor-specific anticancer agent with synergistic effects, in combination with CARTs. PipFcB is an experimental compound that is currently in preclinical evaluation [15]. Synergistic effects of PipFcB in combination with CD19-specific CARTs were observed by chromium-51 $\left({ }^{51} \mathrm{Cr}\right)$ release assay in vitro. Furthermore, induction of intracellular oxidative stress by specific ROS accelerators was identified as a potential mechanism of these synergisms.

\section{Results}

\subsection{The ROS Accelerator PipFcB Increases CART-Mediated Lysis in Lymphoma Cell Lines}

The improved cytotoxic capacity of CARTs, in combination with the ROS accelerator PipFcB, was investigated at different incubation times $(4,8$, and $12 \mathrm{~h})$ in lymphoma cell lines. The combination showed significantly superior lysis compared to the dimethyl sulfoxide (DMSO) vehicle control in the $\mathrm{CD}_{19}{ }^{+}$Burkitt lymphoma cell lines Daudi (Figure 1A) and Raji (Figure 1B) at all evaluated incubation times. The synergistic effect by PipFcB increased in a dose-dependent manner. Highest levels of lysis of the tested time points was achieved after $12 \mathrm{~h}$ incubation, at an effector:target (E:T) ratio of 20:1 and $10 \mu \mathrm{M}$ PipFcB (PipFcB $10 \mu \mathrm{M}$ vs. DMSO: Daudi 75\% $\pm 2 \%$ vs. $39 \% \pm 1 \%, p<0.001$, Raji $92 \% \pm 1 \%$ vs. $25 \% \pm 1 \%, p<0.001)$. PipFcB alone, without CARTs, showed only minimal lysis in the evaluated concentrations and incubation times in Daudi cells (10 $\mu \mathrm{M}$ PipFcB: $5 \% \pm 2 \%$; Figure 2). The direct lysis of tumor cells by PipFcB cannot solely explain this major increase of lysis when combined with CARTs. 

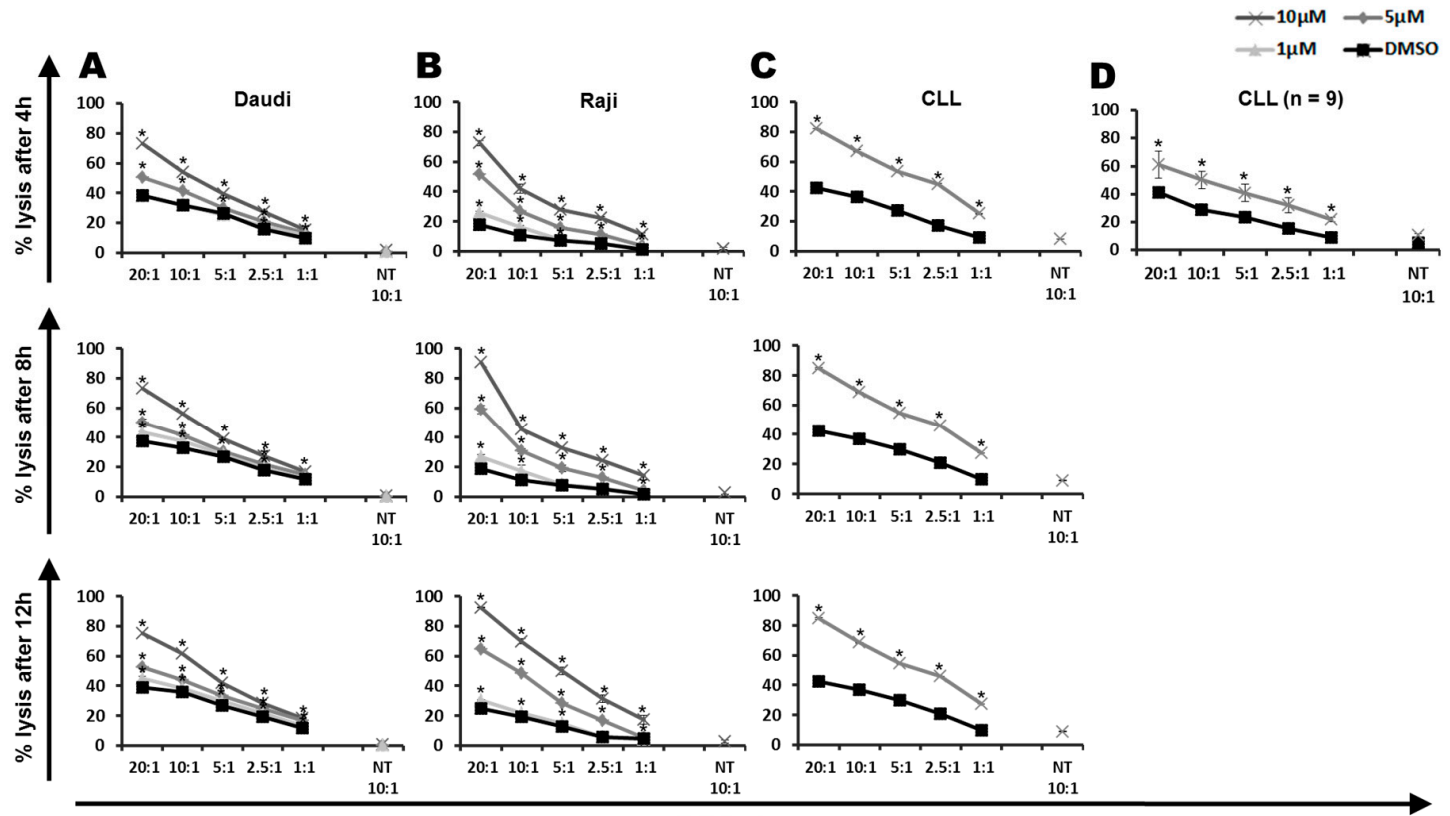

E:T Ratio

Figure 1. Influence of $\mathrm{PipFcB}$ on the cytotoxic capacity of chimeric antigen receptor T cells (CARTs) against Burkitt lymphoma lines and primary chronic lymphocytic leukemia (CLL) cells. Cytotoxicity of CD19-specific CARTs was determined by ${ }^{51} \mathrm{Cr}$ release assay after co-culture with the CD19+ Burkitt lymphoma cell lines Daudi (A) and Raji (B), as well as primary CLL cells (C). Co-incubation with CART cells in different effector to target ratios (20:1, 10:1, 5:1, 2.5:1, 1:1) and non-transduced T cells (NT) was performed for $4 \mathrm{~h}, 8 \mathrm{~h}$, and $12 \mathrm{~h}$. Different concentrations of the specific reactive oxygen species (ROS) accelerator PipFcB $(10 \mu \mathrm{M}, 5 \mu \mathrm{M}, 1 \mu \mathrm{M})$ or dimethyl sulfoxide (DMSO; vehicle) were added simultaneously with CARTs to the culture. Synergistic effects of CARTs with PipFcB were seen in all concentrations $(1-10 \mu \mathrm{M})$ and incubation times (4-12 h). Evaluation of primary CLL cells from nine different patient samples validated the synergistic effects of the combination of CARTs with PipFcB in primary leukemia cells (D). All experiments were performed in triplicates. Primary CLL cells were evaluated in nine independent experiments. Mean values were calculated for each group; error bars indicate standard deviation $(* p<0.05)$.
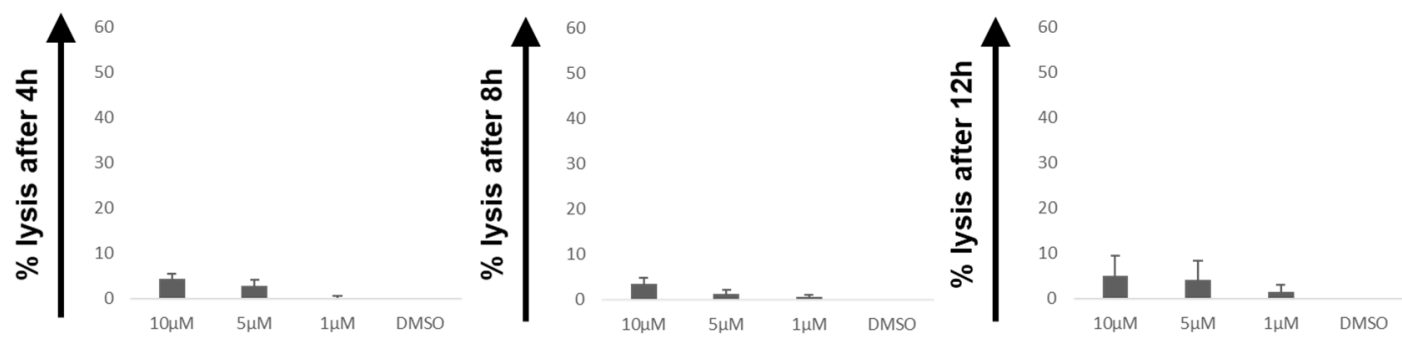

Figure 2. Direct lysis of Daudi cells by PipFcB. Cytotoxicity of PipFcB alone without CARTs was determined by ${ }^{51} \mathrm{Cr}$ release assay after co-culture with Daudi cells for $4 \mathrm{~h}, 8 \mathrm{~h}$, and $12 \mathrm{~h}$. Different concentrations of the specific ROS accelerator PipFcB $(10 \mu \mathrm{M}, 5 \mu \mathrm{M}, 1 \mu \mathrm{M})$ or DMSO (vehicle) were used. PipFcB as a monotherapy achieved only minimal lysis in the evaluated incubation times. All experiments were performed in triplicates and in three independent experiments. Mean values were calculated for each group; error bars indicate standard deviation. 


\subsection{The ROS Accelerator PipFcB Increases CART-Mediated Lysis in Primary CLL Cells}

The improved cytotoxic capacity of CARTs, in combination with $10 \mu \mathrm{M}$ of the ROS accelerator PipFcB, was investigated at different incubation times $(4,8$, and $12 \mathrm{~h})$ in primary CLL cells. The combination showed significantly superior lysis compared to the DMSO vehicle control in $\mathrm{CD} 19^{+}$primary CLL cells in all evaluated incubation times (Figure 1C). Highest increase of lysis was achieved after $12 \mathrm{~h}$ incubation at an E:T ratio of 20:1 (PipFcB $10 \mu \mathrm{M}$ vs. DMSO: $87 \% \pm 1 \%$ vs. $47 \% \pm 1 \%$, $p<0.001)$. This synergistic effect was reproducible in primary CLL cells from nine different patients (PipFcB $10 \mu$ M vs. DMSO: $67 \% \pm 10 \%$ vs. $40 \% \pm 2 \%, p<0.001$; Figure 1D).

\subsection{Pretreatment with the ROS Accelerator PipFcB Sensitizes Lymphoma Cells to CART-Mediated Lysis}

To investigate if pretreatment of leukemia cells with PipFcB may sensitize to CART-mediated lysis, $\mathrm{CD} 19^{+}$Daudi cells were incubated for $4 \mathrm{~h}, 8 \mathrm{~h}$, or $12 \mathrm{~h}$ with different concentrations of PipFcB $(10,5$ and $1 \mu \mathrm{M})$, and afterwards exposed to CARTs at different E:T ratios (20:1, 10:1, 5:1, 2.5:1, 1:1) for $4 \mathrm{~h}$ (Figure 3). Pretreatment for $4 \mathrm{~h}$ significantly increased lysis with $10 \mu \mathrm{M}$ and $5 \mu \mathrm{M}$ PipFcB, compared to the DMSO control (E:T 10:1: $57 \% \pm 1 \%$ and $44 \% \pm 4 \%$ vs. $32 \% \pm 1 \%, p<0.001$ and $p=0.004$; Figure $3 \mathrm{~A}$ ). After $12 \mathrm{~h}$ pretreatment, significantly higher lysis was observed, even with $1 \mu \mathrm{M}$ PipFcB compared to the DMSO control (E:T 10:1: $36 \% \pm 1 \%$ vs. $31 \% \pm 1 \%, p<0.001$; Figure 3 C).

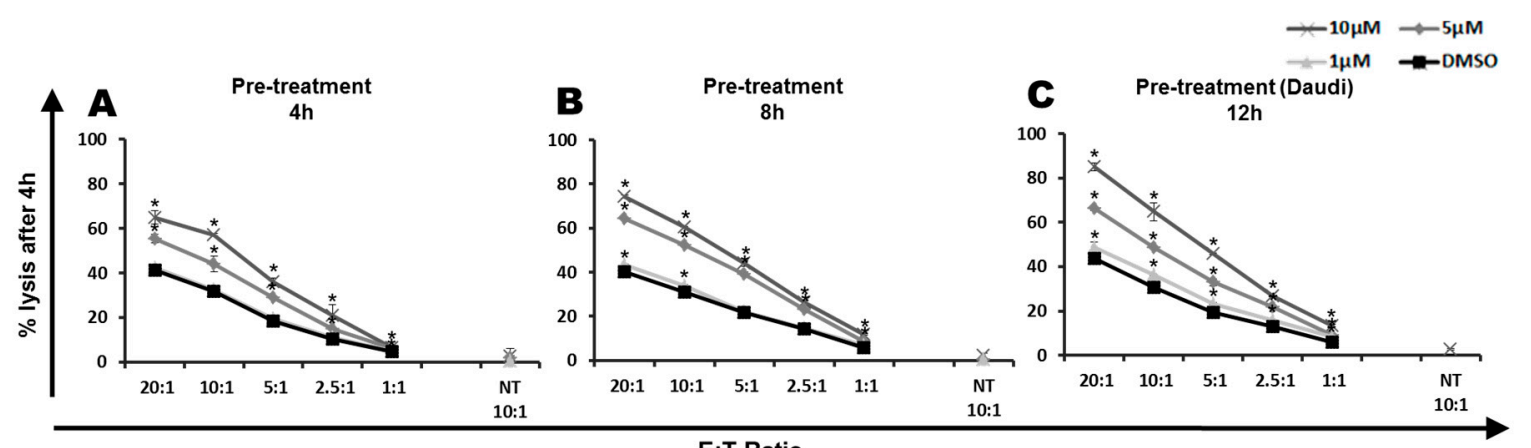

E:T Ratio

Figure 3. Pretreatment of lymphoma cells with PipFcB sensitizes lymphoma cells to lysis by CARTs. CD19+ Daudi cells were first incubated with different concentrations of PipFcB $(10,5$, and $1 \mu \mathrm{M})$ or DMSO (vehicle) for $4 \mathrm{~h} \mathrm{(A),} 8 \mathrm{~h}(\mathbf{B})$, or $12 \mathrm{~h}$ (C). Afterwards, CD19-specific CARTs in different effector to target (E:T) ratios (20:1, 10:1, 5:1, 2.5:1, 1:1) or non-transduced T cells (NT) were added and co-incubated with tumor cells for $4 \mathrm{~h}$. Cytotoxicity was determined by ${ }^{51} \mathrm{Cr}$ release assay. Synergistic effects of CARTs with PipFcB were seen in all concentrations (1-10 $\mu \mathrm{M})$ and pre-treatment durations (4-12 h). All experiments were performed in triplicates. Mean values were calculated for each group; error bars indicate standard deviation $(* p<0.05)$.

\subsection{Increased Tumor Lysis by Combination of Other ROS Accelerators with CARTs}

To investigate if drug-mediated ROS acceleration is responsible for the synergistic effect of $\mathrm{PipFcB}$, the combination of the two unspecific ROS accelerators- $\mathrm{Fe}(\mathrm{HQ})_{2}$ and Buthionine sulfoximine (BSO)-with CD19-specific CARTs was evaluated on CD19+ Daudi and primary CLL cells. The capacity for specific lysis of the weaker ROS accelerators Fe $(\mathrm{HQ})_{2}\left(\mathrm{Fe}(\mathrm{HQ})_{2} 10 \mu \mathrm{M}\right.$ vs. DMSO, E:T 20:1: Daudi $41 \% \pm 2 \%$ vs. $35 \% \pm 2 \%, p<0.001$, CLL $51 \% \pm 2 \%$ vs. $43 \% \pm 1 \%, p<0.001$ ) and BSO (BSO $10 \mu \mathrm{M}$ vs. DMSO, E:T 20:1: Daudi $54 \% \pm 1 \%$ vs. $49 \% \pm 1 \%, p<0.001$, CLL $47 \% \pm 1 \%$ vs. $40 \% \pm 1 \%, p$ $<0.001$ ) combined with CARTs was significantly higher compared to the DMSO vehicle control (Figure 4A-D). However, the additional effect was clearly lower compared to the specific ROS 
accelerator PipFcB. A lower capacity of ROS-generation by $\mathrm{Fe}(\mathrm{HQ})_{2}$ and $\mathrm{BSO}$ may be responsible for these differences. To exclude other mechanisms than ROS-generation alone for synergistic lysis of aminoferrocene-based prodrugs when combined with CARTs, the effect of ferrocene, the base compound of $\mathrm{PipFcB}$, in combination with $\mathrm{CARTs}$ was evaluated. Ferrocene has a high structural similarity to PipFcB but lacks the capacity of ROS-generation. This combination did not influence specific lysis of CARTs (Figure 4E-F).

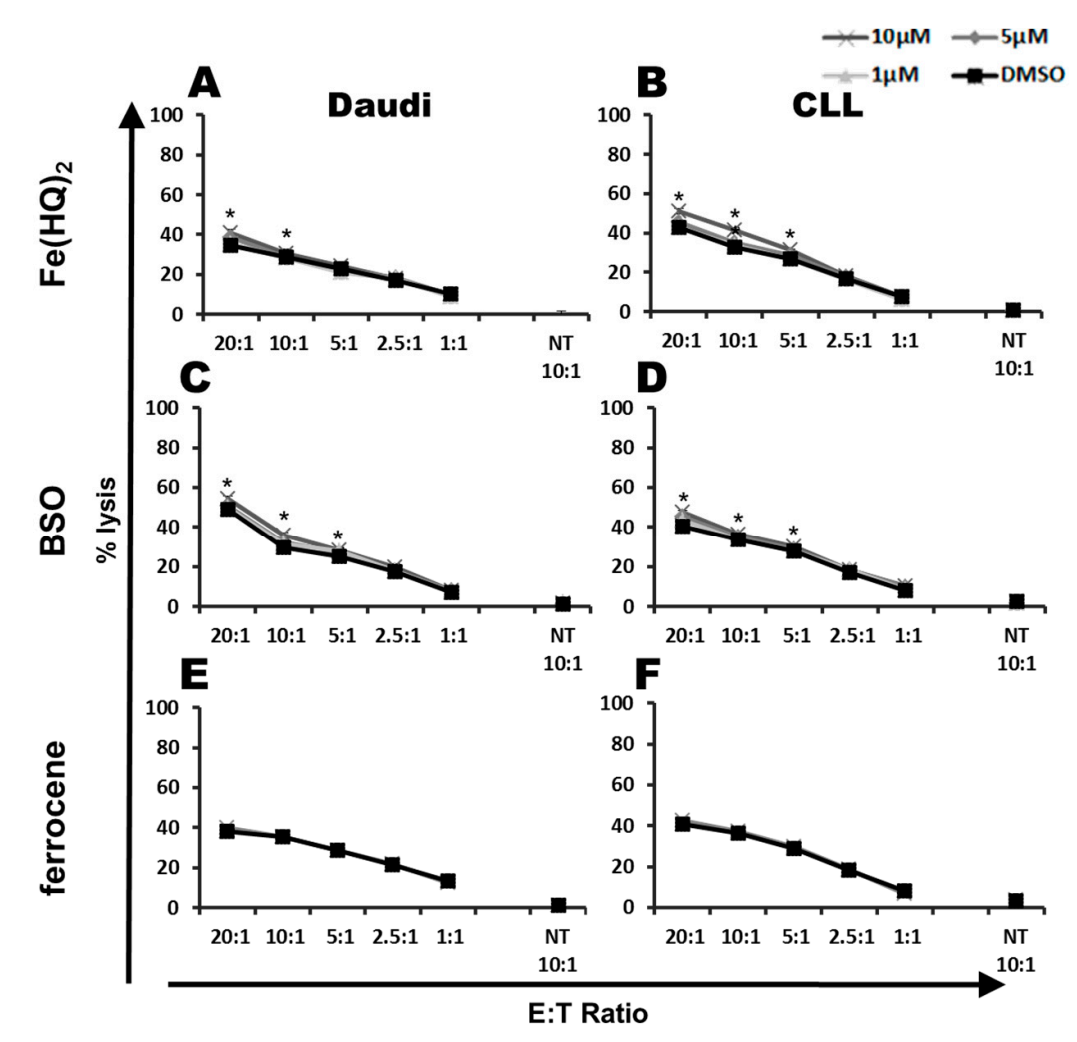

Figure 4. Influence of unspecific ROS accelerators and ferrocene on the cytotoxic capacity of CARTs. Cytotoxicity of CD19-specific CARTs was determined by ${ }^{51} \mathrm{Cr}$ release assay after co-culture with the $\mathrm{CD} 19^{+}$Burkitt lymphoma cell line Daudi $(\mathbf{A}, \mathbf{C}, \mathbf{E})$, as well as CD19 ${ }^{+}$primary CLL cells $(\mathbf{B}, \mathbf{D}, \mathbf{F})$. Co-incubation with CARTs in different E:T ratios (20:1, 10:1, 5:1, 2.5:1, 1:1) and non-transduced T cells (NT) was performed for $4 \mathrm{~h}$. Different concentrations of the unspecific ROS accelerators $(10 \mu \mathrm{M}, 5 \mu \mathrm{M}$, $2.5 \mu \mathrm{M}$ ) or DMSO (vehicle) were added simultaneously with CARTs to the culture. The unspecific ROS accelerators $\mathrm{Fe}(\mathrm{HQ})_{2}(\mathbf{A}, \mathbf{B})$ and Buthionine sulfoximine (BSO; C,D) slightly increased the cytotoxic capacity of CARTs, but to a significantly lesser extent compared to specific ROS accelerators such as PipFcB. Ferrocene, the base compound of PipFcB without the capacity of ROS generation, did not influence specific tumor lysis by CARTs. All experiments were performed in triplicates. Mean values were calculated for each group; error bars indicate standard deviation $\left({ }^{*} p<0.05\right)$.

\subsection{Influence of PipFcB on Lysis by CARTs in CD19- Cells}

To exclude excessive increase of unspecific lysis by CD19-specific CARTs in the presence of PipFcB, cytotoxicity against $\mathrm{CD} 19^{-}$multiple myeloma cells (RPMI-8226) was evaluated. PipFcB significantly increased unspecific lysis by PipFcB compared to the DMSO control (10 $\mu$ M PipFcB, E:T 10:1: $14 \% \pm 2 \%$ vs. $8 \% \pm 1 \%, p<0.001$; Figure 5), however, to a clearly lesser extent compared to effects on $\mathrm{CD}^{+} 9^{+}$cells. 


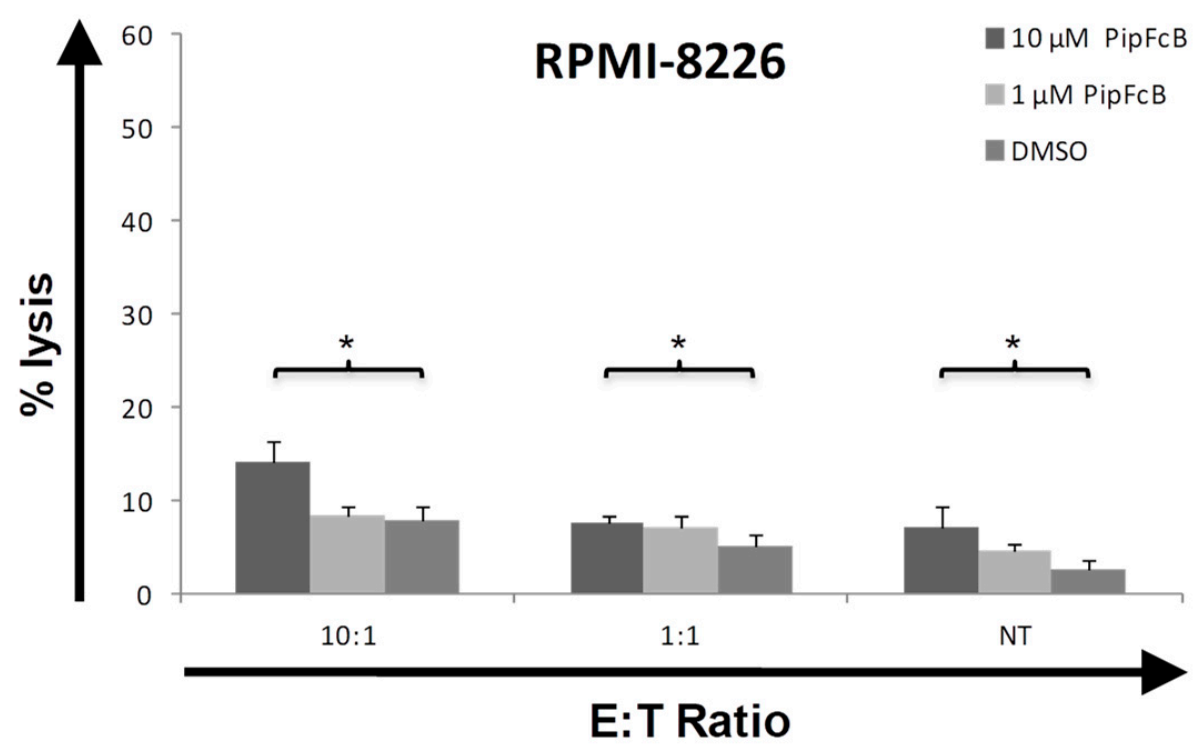

Figure 5. Influence of PipFcB on the cytotoxic capacity of CARTs against CD19- cells. Cytotoxicity of CD19-specific CARTs was determined by ${ }^{51} \mathrm{Cr}$ release assay after co-culture with the CD19- multiple myeloma cell line RPMI-8226. Co-incubation with CARTs in different E:T ratios (10:1, 1:1) and non-transduced T cells (NT) was performed for $4 \mathrm{~h}$. Different concentrations of the specific ROS accelerator PipFcB $(10 \mu \mathrm{M}, 1 \mu \mathrm{M})$ or DMSO (vehicle) were added simultaneously with CARTs to the culture. PipFcB significantly increased unspecific lysis by CD19-specific CARTs and NTs in CD19multiple myeloma cells. All experiments were performed in triplicates. Mean values were calculated for each group; error bars indicate standard deviation $\left({ }^{*} p<0.05\right)$.

\subsection{No Influence of PipFcB on Degranulation or Intracellular Cytokine Production of CARTs}

To determine if degranulation or cytokine production is influenced by ROS acceleration, CD107a expression and intracellular cytokine production of tumor necrosis factor-alpha (TNF- $\alpha$ ), interferon-gamma (IFN- $\gamma$ ) and interleukin-2 (IL-2) was determined in the presence or absence of PipFcB. No induction of CD107a expression or intracellular cytokine production by PipFcB could be observed in CARTs after stimulation with the CD19+ Raji and Daudi cells (Figure 6A-C). The only significant difference by $10 \mathrm{mM}$ PipFcB compared to the solvent control was observed for CD107a expression on CARTs stimulated with primary CLL cells (PipFcB $10 \mu \mathrm{M}$ vs. DMSO 50\% $\pm 6 \%$ vs. 29\% $\pm 3 \%, p<0.01$; Figure $6 \mathrm{D}$ ). No relevant changes in CD107a expression or cytokine production were observed by stimulation with CD19- RPMI-8226 cells in the presence or absence of PipFcB (Figure 6E).

\subsection{Malignant Lymphoma Cells are More Susceptible to PipFcB-Mediated Oxidative Stress}

The generation of intracellular oxidative stress by PipFcB in tumor cells, as well as CARTs and non-transduced T cells, was investigated. Dichloro-dihydro-fluorescein diacetate (DCFH-DA) is a cell-permeable non-fluorescent probe that is oxidized to fluorescent $2^{\prime}, 7^{\prime}$-dichlorofluorescein in the presence of ROS. This effect can be utilized as an indicator for intracellular oxidative stress. Raji cells were significantly more susceptible to PipFcB-mediated induction of oxidative stress, compared to CARTs as well as non-transduced T cells (Figure 7). 


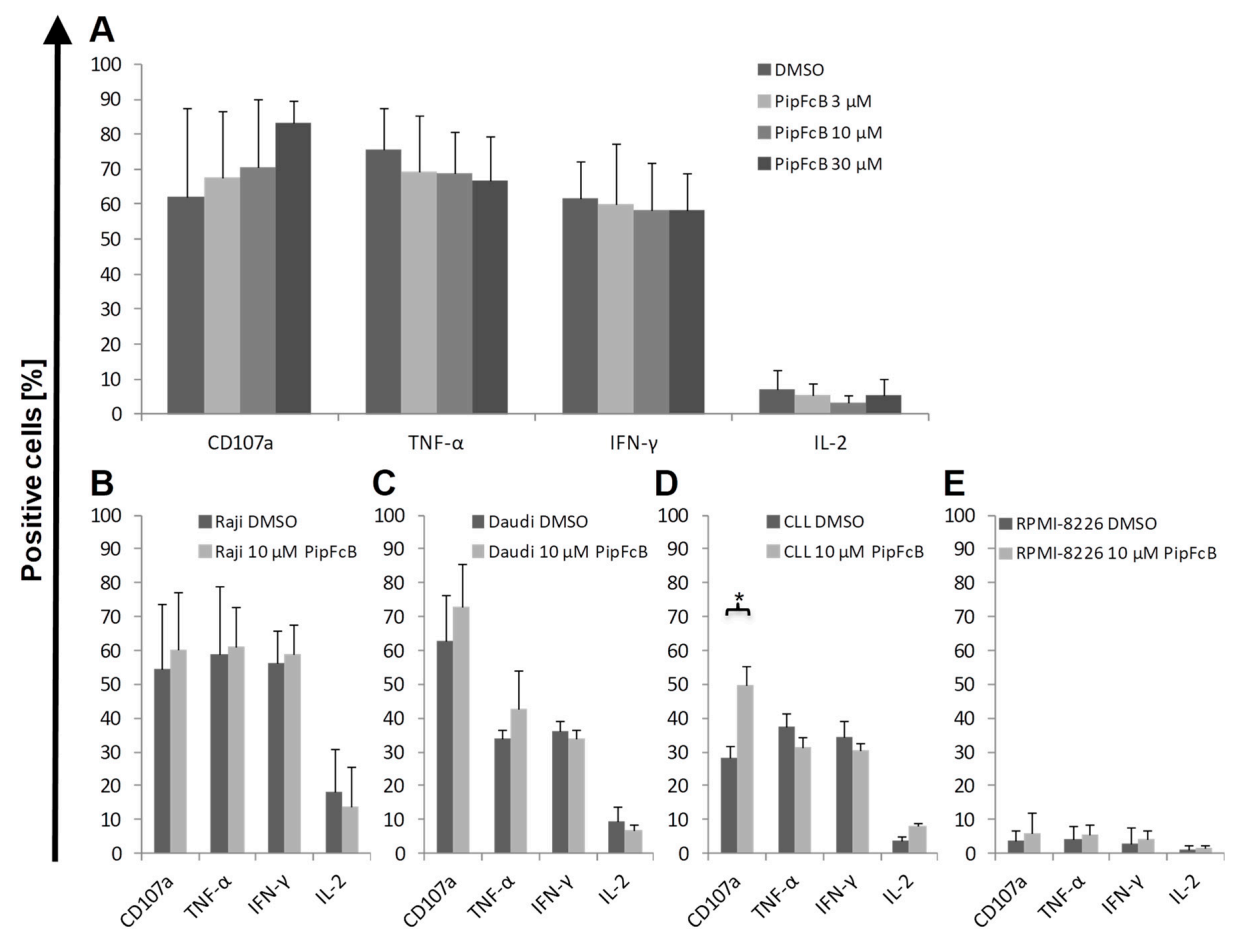

Figure 6. Influence of PipFcB on CART degranulation and intracellular cytokine production. CARTs were co-cultured for $6 \mathrm{~h}$ with Raji cells in the presence of PipFcB in different concentrations $(3 \mu \mathrm{m}$, $10 \mu \mathrm{m}, 30 \mu \mathrm{M}$ ). DMSO served as solvent control (A). Experiments were performed in three independent experiments. No differences in CD107a expression and intracellular production of TNF- $\alpha$, IFN- $\gamma$ and IL-2 was observed in the cultures supplemented with PipFcB, compared to the solvent control. $10 \mu \mathrm{M}$ of PipFcB was further evaluated with CART stimulation by Raji $(n=6$; B), Daudi $(n=3$; C), primary CLL $(n=3 ; \mathbf{D})$, and RPMI-8226 cells $(n=3 ; \mathbf{E})$. No differences in CD107a expression and intracellular production of TNF- $\alpha$, IFN- $\gamma$ and IL-2 were observed in Raji-, Daudi-, or RPMI-8226-stimulated CART cultures supplemented with PipFcB, compared to the solvent control. The only significant difference by PipFcB was observed for CD107a expression on CARTs stimulated with primary CLL cells. Mean values were calculated for each group; error bars indicate standard deviation $\left({ }^{*} p<0.05\right)$.
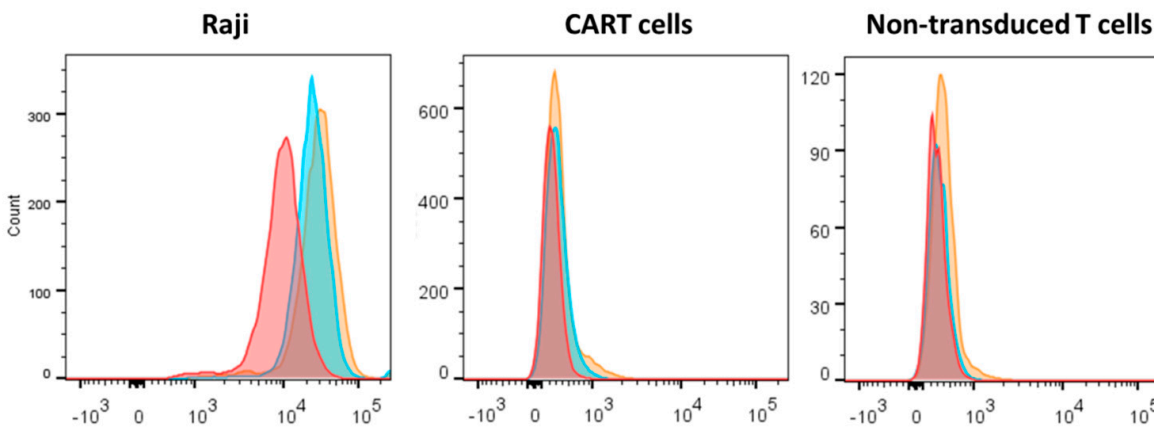

DHFH-DA (FITC)

Figure 7. Generation of oxidative stress by PipFcB in malignant lymphoma cells, as well as CARTs and non-transduced T cells. After staining with Dichloro-dihydro-fluorescein diacetate (DCFH-DA), Raji cells-as well as CARTs and non-transduced T cells-were incubated with $10 \mu \mathrm{M}$ or $30 \mu \mathrm{M}$ PipFcB for four hours. DMSO served as solvent control. Raji cells exhibited a significantly higher induction of PipFcB-mediated oxidative stress. Representative histograms of three independent experiments are shown. 


\subsection{Influence of Long-Term PipFcB Exposure on CARTs}

In order to study long-term effects of PipFcB on survival and phenotype, CARTs from six healthy donors were exposed for $48 \mathrm{~h}$ to $1 \mu \mathrm{M}$ of $\mathrm{PipFcB}$, the lowest dose with synergistic effects and little toxicity to healthy lymphocytes. Treatment of PBMCs from healthy donors $(n=3)$ and primary CLL cells $(n=9)$ showed that $10 \mu \mathrm{M}$ of PipFcB is more specific in killing primary CLL cells after exposure for $48 \mathrm{~h}$, but can also harm healthy PBMCs (viability PBMC vs. CLL $52 \% \pm 19 \%$ vs. $11 \% \pm 13 \%, p=0.047$, Figure 8A). $1 \mu \mathrm{M}$ of PipFcB also displayed specific activity against CLL cells, while sparing healthy PBMCs (viability PBMC vs. CLL $82 \% \pm 9 \%$ vs. $45 \% \pm 31 \%, p=0.01$; Figure $8 \mathrm{~A}$ ). In addition, it showed synergistic effects with CARTs in short-term ${ }^{51} \mathrm{Cr}$ release assay (Figure 1).

For long-term culture, CARTs were cultured in medium supplemented with $10 \%$ human serum to increase survival and mimic in vivo conditions more accurately. $1 \mu \mathrm{M}$ of PipFcB did not influence viability of CARTs $(n=12)$ after cultivation for $48 \mathrm{~h}$ (Figure $8 \mathrm{~B}$ ).

There was no relevant effect of $1 \mu \mathrm{M}$ PipFcB on T cell subsets $(n=12$; Figure $8 \mathrm{C})$. In addition, expression of the exhaustion marker PD-1 was not affected by $1 \mu \mathrm{M}$ PipFcB after $48 \mathrm{~h}$ of co-incubation $(n=12$; Figure 8D). However, a trend towards lower T-cell immunoglobulin and mucin-domain containing-3 (TIM-3) expression in CARTs after exposure to PipFcB for $48 \mathrm{~h}$ was observed $(n=12$; without vs with $1 \mu \mathrm{M}$ PipFcB $17 \% \pm 16 \%$ vs. $12 \% \pm 14 \%, p=0$. 1 ; Figure $8 \mathrm{D})$.
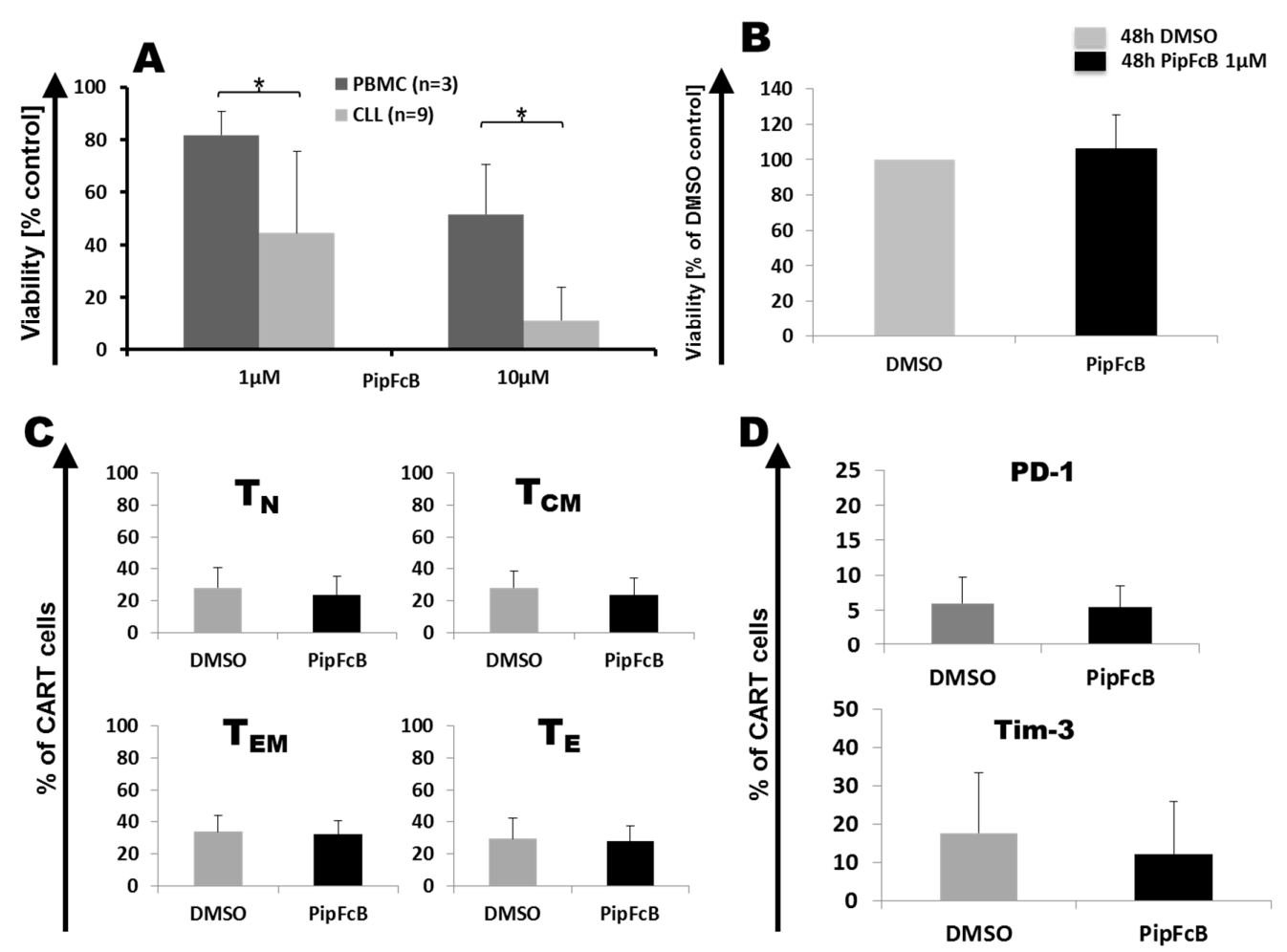

Figure 8. Long-term effects of the ROS accelerator PipFcB on primary CLL cells, as well as peripheral blood mononuclear cells (PBMCs) and CARTs. Healthy donor PBMCs $(n=3)$ and primary CLL cells $(n=9)$ were incubated with $10 \mu \mathrm{M}$ and $1 \mu \mathrm{M}$ PipFcB for 48 h. Viability was determined by quantification of ATP. $10 \mu \mathrm{M}$ and $1 \mu \mathrm{M}$ of PipFcB specifically killed CLL cells (A). However, $10 \mu \mathrm{M}$ of PipFcB significantly reduced the viability of PBMCs. Therefore, $1 \mu \mathrm{M}$ PipFcB was used to study long-term effects on survival and phenotype of CARTs. $1 \mu \mathrm{M}$ of PipFcB did not influence viability of CARTs determined by NearIR in flow cytometry after cultivation for $48 \mathrm{~h}(n=12)(\mathbf{B})$. In addition, no relevant effect of $1 \mu \mathrm{M}$ PipFcB on naïve-like $\left(\mathrm{T}_{\mathrm{N}}\right)$, central memory-like $\left(\mathrm{T}_{\mathrm{CM}}\right)$, effector-memory-like $\left(\mathrm{T}_{\mathrm{EM}}\right)$, or effector-like $\left(\mathrm{T}_{\mathrm{E}}\right)$ CARTs $(n=12)(\mathrm{C})$ - or on the expression of the exhaustion markers PD-1 and TIM-3 $(n=12)$ (D)-was observed. Mean values were calculated for each group; error bars indicate standard deviation $\left({ }^{*} p<0.05\right)$. 


\section{Discussion}

Despite encouraging results, resistance of tumor cells against CARTs occurs. To therapeutically exploit immunosuppressive influences of the tumor-microenvironment, we evaluated synergistic influences and functional effects of ROS accelerators in combination with CD19-specific CARTs. Potential synergistic effects of CARTs in combination with tumor-specific ROS accelerators were identified. These are likely to be related to the induction of ROS generation by ROS accelerators. Combination therapy approaches may be a valuable option to overcome treatment resistance against CARTs.

Reports from CLL patients treated with CD19-specific CARTs have demonstrated very encouraging effects and have been shown to provide long-term remissions [18-20]. However, compared to patients treated for diffuse large B cell lymphoma [21,22] or acute lymphoblastic leukemia [23], response rates ranging between 30-70\% seem to be lower in CLL patients [18-20]. Therefore, optimization of CART therapy may improve the outcome of those patients. The combination of CARTs with small molecules or monoclonal antibodies currently presents as a major focus in adoptive immunotherapy. The Bruton's tyrosine kinase (BTK) inhibitor ibrutinib [6,24], or immunomodulatory drugs such as lenalidomide [5,7], have been suggested to boost CART activity. Consequently, clinical trials with a combinatorial approach have been initiated (NCT02640209, NCT03070327).

For targeted cancer treatment, approaches exploiting specific alterations of malignant cells for effective treatment whilst displaying little off-target toxicity are highly desirable. Lymphoid malignancies are known to display increased ROS levels. CLL cells, especially, seem to be exceptionally sensitive to ROS-generating compounds [25]. The mitochondrial metabolism was identified as one of the main sources for intracellular ROS accumulation and might be responsible for disease progression [26]. Therefore, this metabolic alteration represents a hallmark of cancer, and ROS may be an optimal therapeutic target in CLL. Pathogen-primed neutrophils and monocytes/macrophages can have relatively high ROS levels. Therefore, immunosuppression may be a side effect of tumor-specific ROS accelerators such as PipFcB. However, no severe immunosuppression or side effects against heart, liver, or kidney were observed in previously performed in vivo experiments in mouse models [15].

The ROS accelerator PipFcB significantly increased CART-mediated lysis in lymphoma cell lines, as well as primary CLL cells. Importantly, direct PipFcB-mediated lysis of tumor cells alone cannot explain significantly increased lysis in combination therapy, suggesting synergistic activities beyond additive effects. In addition, pretreatment of lymphoma cells with ROS accelerators sensitized malignant cells to lysis by CARTs. This indicates that the main effect of ROS accelerators is located within the target cells. This observation is supported by the fact that $\mathrm{PipFcB}$ significantly increased intracellular oxidative stress in tumor cells, whilst it did not influence non-transduced $\mathrm{T}$ cells or CARTs. Furthermore, cytokine secretion of CARTs was not affected by ROS accelerators. The increased degranulation was only observed in CARTs stimulated with primary CLL cells. Further investigation of this finding may be of interest. The unspecific ROS accelerators, $\mathrm{Fe}(\mathrm{HQ})_{2}$ and $\mathrm{BSO}$, were also able to achieve synergistic activities in combination with CARTs, even though their effect was significantly lower than that of the specific ROS accelerator PipFcB. In contrast, ferrocene, the base compound of PipFcB, showed no effect against tumor cells. Therefore, intracellular ROS generation in tumor cells is likely to be mainly responsible for synergistic activities between CARTs and PipFcB.

In previous studies, we demonstrated that aminoferrocene-based ROS accelerators-including PipFcB - are specific for tumor cells, whilst displaying little toxicity towards healthy PBMCs [14-16]. In the current study we confirmed this finding, demonstrating that PipFcB is significantly more toxic towards primary CLL cells compared to healthy PBMCs. However, $10 \mu \mathrm{M}$ of PipFcB still displayed relevant toxicity to PBMCs, as well as significantly increased unspecific lysis by CARTs in CD19cells-even though, to a clearly lesser extent compared to lysis of $\mathrm{CD}_{1} 9^{+}$cells. In contrast, $1 \mu \mathrm{M}$ of PipFcB that also achieved synergistic effects when combined with CARTs had little effects on viability, $\mathrm{T}$ cell differentiation, and expression of exhaustion markers. Therefore, analysis upon lower concentrations may be more suitable for in vivo evaluation of PipFcB in combination with CARTs in 
the future. Anti-tumor activity of PipFcB in mouse models with little toxicity against healthy tissue was demonstrated previously [15]. Optimization of currently available ROS accelerators for increased tumor specificity may reduce off-target toxicity of these compounds. This could be, for example, achieved by the addition of additional tumor-specific activation triggers such as hypoxia [27].

A limitation of this study would be the fact that the evaluation of combination therapy was carried out only in artificial two-dimensional cell culture conditions, which do not reflect the hypoxic conditions in the bone marrow or in the lymph node in vivo. Additional investigations in more complex culture conditions better reflecting the three-dimensional structure of tumor cells in vivo, including the tumor microenvironment [28], may help to further elaborate the mechanisms of ROS accelerator-mediated synergisms with CARTs. Furthermore, evaluation of ROS accelerators in combination with CARTs in mouse models is necessary to prove in vivo efficacy of this combinatory treatment approach.

CARTs might encounter significantly higher ROS levels in the immunosuppressive tumor-microenvironment in lymph nodes or the bone marrow. This could lead to decreased CART-mediated anti-tumor activity. Protection of CARTs with implementation of catalase in the chimeric antigen receptor (CAR) construct that can provide additional anti-oxidative capacity for CARTs [29], for example, might be helpful to overcome this limitation. Furthermore, an increased anti-oxidative capacity of CARTs may reduce the toxicity of ROS accelerators. Combination of such fourth-generation CARTs with tumor-specific ROS accelerators or other drugs with synergistic activities are likely to represent the future of CART-based treatment approaches [30].

In conclusion, the combination of ROS accelerators with CARTs might be an option to exploit the immunosuppressive tumor-microenvironment for optimized CART therapy.

\section{Materials and Methods}

\subsection{Cell Lines}

CD19+ Burkitt lymphoma (Daudi, Raji) and CD19- multiple myeloma (RPMI-8226) cell lines were obtained from DMSZ (German Collection of Microorganisms and Cell Cultures, Braunschweig, Germany) and cultured in RPMI 1640 supplemented with 10\% fetal bovine serum (FBS) and $2 \mathrm{mM}$ L-glutamine (all Thermo Fisher Scientific, Waltham, MA, USA) at $37^{\circ} \mathrm{C}$ and $5 \% \mathrm{CO}_{2}$.

\subsection{Primary Cells}

Peripheral blood (PB) samples were collected from healthy donors (blood bank Mannheim, DRK-Blutspendedienst Baden-Württemberg-Hessen, Heidelberg, Germany) and CLL patients (University Hospital Heidelberg, Heidelberg, Germany). PBMCs were purified by ficoll density gradient (Linaris, Dossenheim, Germany) and cryopreserved. Informed consent was obtained from all patients according to the Declaration of Helsinki, and approval for the study was obtained from the Ethics Committee of the University of Heidelberg (16.06.2016; S-254/2016). CLL cells were cultured in RPMI 1640 supplemented with 10\% Human Serum (Sigma-Aldrich, St. Louis, MO, USA) and 2 mM L-glutamine (Thermo Fisher Scientific).

\subsection{Retroviral Vector Production}

CD19.CAR-CD28-CD137zeta third generation retroviral vector was produced by co-transfecting 293T cells with the specific retroviral vector plasmid ( $3.75 \mu \mathrm{g})$, PegPam3 plasmid containing gag-pol $(3.75 \mu \mathrm{g})$ and RDF plasmid containing the envelope $(2.5 \mu \mathrm{g})$. Plasmids were kindly provided by Professor Malcolm Brenner, Center for Cell and Gene Therapy, Baylor College of Medicine, Houston, TX, USA. 


\subsection{CD19-CART Generation and Culture}

CD19-CART cells were generated as described previously [31-33]. In brief, PBMCs were thawed, cultured in 50\% RPMI 1640 (Thermo Fisher Scientific) and 50\% Click's Medium (EHAA) (Irvine Scientific, Santa Ana, CA, USA), with 10\% FBS (Thermo Fisher Scientific) and 2 mM L-glutamine (Thermo Fisher Scientific), and activated in 24-well plates (Corning, Wiesbaden, Germany) coated with anti-CD3 (OKT3; Biozol, Eching, Germany) and anti-CD28 (Fresenius, Bad Homburg, Germany) antibodies. On day 2, culture medium was supplemented with $4.4 \times 10^{3} \mathrm{U} / \mathrm{mL}$ IL-7 and $100 \mathrm{U} / \mathrm{mL}$ IL-15 (both R\&D Systems, Minneapolis, MN, USA). On day 3, activated T cells were transduced with the CD19.CAR-CD28-CD137zeta third generation retroviral vector in 24-well plates (Corning, Corning, NY, USA) coated with retronectin (Takara Bio, Shiga, Japan). On day 14, CARTs were cryopreserved in FBS (Thermo Fisher Scientific) + 10\% DMSO (Sigma-Aldrich).

\subsection{Compounds}

The specific ROS accelerator PipFcB was synthesized as described previously [15]. Ferrocene (Sigma-Aldrich), the basic substance of aminoferrocene-based prodrugs without the function of ROS generation, served as a negative control [16]. The unspecific ROS accelerators Buthionine sulfoximine (BSO) and $\mathrm{Fe}(\mathrm{HQ})_{2}$ (Sigma-Aldrich) were used as positive controls. Compounds were dissolved in DMSO at a final concentration of $10 \mathrm{mM}$ and stored at $-20^{\circ} \mathrm{C}$.

\subsection{Chromium-51 Release Assay}

Cytotoxic function of CARTs was determined using ${ }^{51} \mathrm{Cr}$ release assay. $\mathrm{CD} 19^{+}$target cells were labeled with ${ }^{51} \mathrm{Cr}$ (Hartmann Analytic, Braunschweig, Germany) for $2 \mathrm{~h}$, followed by co-incubation with CD19-specific CARTs in 96-well U-bottom microplates (Greiner Bio-One, Frickenhausen, Germany) for different incubation times $(4,8$, and $12 \mathrm{~h})$. Different effector to target (E:T) ratios (20:1, 10:1, 5:1, 2.5:1, 1:1, and non-transduced T cells 10:1) with or without ROS accelerators (1-10 $\mu \mathrm{M})$ were used. Maximum ${ }^{51} \mathrm{Cr}$ release was assessed by addition of 1\% Triton X-100 (Sigma-Aldrich). Background release was measured in the absence of CART cells. Culture supernatant was collected and diluted with Ultima Gold liquid scintillation cocktail (PerkinElmer, Waltham, Ma, USA). ${ }^{51} \mathrm{Cr}$ release was analyzed by a 1414 WinSpectral liquid scintillation counter (PerkinElmer). All experiments were performed in triplicates. Specific lysis of ${ }^{51} \mathrm{Cr}$ release was calculated as following: $\left(\left({ }^{51} \mathrm{Cr}\right.\right.$ release in the test well background ${ }^{51} \mathrm{Cr}$ release)/(maximum ${ }^{51} \mathrm{Cr}$ release - background ${ }^{51} \mathrm{Cr}$ release $\left.)\right) \times 100$.

\subsection{Immunophenotyping and Intracellular Cytokine Staining}

Flow cytometry was performed on an LSRII device (BD Biosciences, Franklin Lakes, NJ, USA) and analyzed using FlowJo software (FlowJo, Ashland, OR, USA). Dead cells were excluded with the LIVE/DEAD ${ }^{\mathrm{TM}}$ fixable near-infrared(-IR) dead cell stain kit (APC-Cy7; Thermo Fisher Scientific). The goat $\mathrm{F}(\mathrm{ab}) 2$ anti-human IgG (H+L) PE antibody (Dianova, Hamburg, Germany) was used for CD19-specific CAR expression. The following antibodies were used for immunophenotyping of surface markers: CD45RA-FITC, CCR7-PE-Cy7, CD8-Pacific Blue, PD-1-Alexa Fluor 488, Tim-3-Brilliant Violet 421 (all Biolegend, San Diego, CA, USA), CCR7-PE-Cy7, CD4-Alexa Fluor 700 (all eBioscience, San Diego, CA, USA), and CD3-AmCyan (V500) (BD Biosciences). Naïve-like $T$ cells $\left(T_{N}\right)$ were defined as CD45RA+CCR7+; central memory-like ( $\mathrm{T}_{\mathrm{CM}}$ ) as CD45RA-CCR7+; effector memory-like ( $\mathrm{T}_{\mathrm{EM}}$ ) as CD45RA-CCR7-; and effector-like $\mathrm{T}\left(\mathrm{T}_{\mathrm{E}}\right)$ cells as CD45RA+CCR7- $\mathrm{T}$ cells. Fixation of the cells after staining was performed with Dulbecco's phosphate buffered saline (PBS; Sigma-Aldrich) containing 1\% paraformaldehyd (PFA; Morphisto, Frankfurt am Main, Germany) and $3 \mathrm{mM}$ ethylenediaminetetraacetic acid (EDTA; Sigma-Aldrich). Intracellular cytokine staining was performed as described previously [31]. In brief, cells were co-cultured with CD19-positive Daudi cells for $6 \mathrm{~h}$ in 96-well U-bottom microplates (Greiner BioOne, Frickenhausen, Germany). Brefeldin A (Biolegend) was used for intracellular cytokine retention according to the manufacturer's protocol ( $5 \mathrm{~h}$ incubation 
at $37^{\circ} \mathrm{C}$ ). Fixation and permeabilization was performed with fix/perm solution and permeabilization buffer of the FoxP3 staining buffer set (Miltenyi Biotec, Bergisch Gladbach, Germany). Anti-interferon (IFN)- $\gamma$-Alexa Fluor 488 (Biolegend) and anti-tumor necrosis factor (TNF)- $\alpha$-BV421 (BD Biosciences) were used for cytokine staining.

\subsection{Evaluation of Intracellular Oxidative Stress}

Cells were incubated for 5 min with $10 \mu \mathrm{M}$ DCFH-DA at $37{ }^{\circ} \mathrm{C}$. After washing with PBS, Raji cells-as well as CART cells and non-transduced T cells-were incubated with 10 or $30 \mu \mathrm{M}$ PipFcB for $4 \mathrm{~h}$ at $37^{\circ} \mathrm{C}$. DMSO served as solvent control. Flow cytometry was performed on an LSRII device (BD Biosciences) after stained for CD3-Alexa Flour 700 (Biolegend), CD20-Brilliant Violet 510 (Biolegend), and F(ab)2 IgG-PE (Dianova). Dead cells were excluded with the LIVE/DEAD ${ }^{\mathrm{TM}}$ fixable near-IR dead cell stain kit (Thermo Fisher Scientific).

\subsection{Statistical Analysis}

Statistical analyses were performed using Excel 2007 (Microsoft, Redmond, WA, USA). $p$-values were calculated using the parametric two-tailed t-test. Tests for two samples with equal variance (Figure $8 \mathrm{~A}$ ) or paired samples (other figures) were used. $p$-values $<0.05$ were considered statistically significant. Graphs and tables were designed by Excel (Microsoft) and Origin Software 2016 (OriginLab Corporation, Washington, MA, USA). If not mentioned otherwise, results are presented as average \pm standard deviation (SD).

Author Contributions: Conceptualization, H.J.Y., L.S., and M.S.; methodology, H.J.Y., Y.L., and L.S.; experimental design discussion, M.-L.S., L.W., J.-M.H., B.N., A.H.-K., S.W., U.G., and A.S.; data analysis, H.J.Y., Y.L., and L.S.; crucial reagents, A.M., P.D., C.M.-T.; writing-original draft preparation, H.J.Y. and L.S.; writing-review and editing, all authors; visualization, H.J.Y., Y.L., and L.S.; supervision, M.S. and L.S.; project administration, L.S.; funding acquisition, A.M., M.S., and L.S.

Funding: This work was funded in part by the government of Baden-Württemberg (Anschubfinanzierung zur Etablierung eines Netzwerks "Brückeninstitutionen für die Regenerative Medizin in Baden-Württemberg", Kapitel 1403 Tit.Gr. 74) and by the DKTK (Deutsches Konsortium für Translationale Krebsforschung). L.S. was supported by the Physician Scientist-Program of the Medical Faculty of Heidelberg, the NCT Heidelberg School of Oncology (HSO), and the Clinician Scientist Program of the German Society of Internal Medicine (DGIM). A.M. acknowledges funding from the German Research Council (DFG, MO 1418 / 7-1) and the Emerging Field Initiative of Friedrich-Alexander-University of Erlangen-Nürnberg (grant 3_Nat_01, "Chemistry in live cells"), as well as partial funding from the EU-project RISE-CLATHROPROBES (H2O2-MSCA-RISE-2017, Project 778245).

Acknowledgments: We are grateful to all patients who provided primary samples for this study.

Conflicts of Interest: The authors declare no conflict of interest.

\section{Abbreviations}

$\begin{array}{ll}{ }^{51} \mathrm{Cr} & \text { Chromium-51 } \\ \text { BSO } & \text { Buthionine sulfoximine } \\ \text { BTK } & \text { Bruton's tyrosine kinase } \\ \text { CAR } & \text { Chimeric antigen receptor } \\ \text { CART } & \text { Chimeric antigen receptor T cell } \\ \text { CLL } & \text { Chronic lymphocytic leukemia } \\ \text { CTLA4 } & \text { Cytotoxic T-lymphocyte-associated antigen } 4 \\ \text { DCFH-DA } & \text { Dichloro-dihydro-fluorescein diacetate } \\ \text { DMSO } & \text { dimethyl sulfoxide } \\ \text { FBS } & \text { Fetal bovine serum } \\ \text { IFN- } \gamma & \text { Interferon-gamma } \\ \text { IL-2 } & \text { Interleukin-2 }\end{array}$




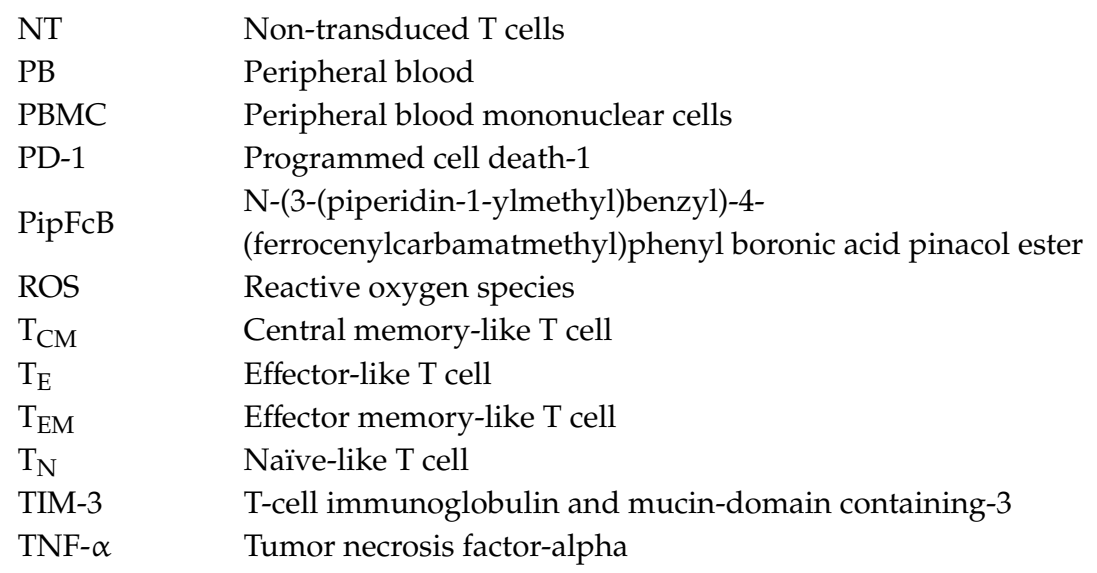

\section{References}

1. Schubert, M.L.; Huckelhoven, A.; Hoffmann, J.M.; Schmitt, A.; Wuchter, P.; Sellner, L.; Hofmann, S.; Ho, A.D.; Dreger, P.; Schmitt, M. Chimeric Antigen Receptor T Cell Therapy Targeting CD19-Positive Leukemia and Lymphoma in the Context of Stem Cell Transplantation. Hum. Gene Ther. 2016, 27, 758-771. [CrossRef]

2. Jacoby, E.; Nguyen, S.M.; Fountaine, T.J.; Welp, K.; Gryder, B.; Qin, H.; Yang, Y.; Chien, C.D.; Seif, A.E.; Lei, H.; et al. CD19 CAR immune pressure induces B-precursor acute lymphoblastic leukaemia lineage switch exposing inherent leukaemic plasticity. Nat. Commun. 2016, 7, 12320. [CrossRef]

3. Sotillo, E.; Barrett, D.M.; Black, K.L.; Bagashev, A.; Oldridge, D.; Wu, G.; Sussman, R.; Lanauze, C.; Ruella, M.; Gazzara, M.R.; et al. Convergence of Acquired Mutations and Alternative Splicing of CD19 Enables Resistance to CART-19 Immunotherapy. Cancer Discov. 2015, 5, 1282-1295. [CrossRef]

4. Wang, J.; Hu, Y.; Huang, H. Acute lymphoblastic leukemia relapse after CD19-targeted chimeric antigen receptor T cell therapy. J. Leukoc. Biol. 2017, 102, 1347-1356. [CrossRef]

5. Wang, X.; Walter, M.; Urak, R.; Weng, L.; Huynh, C.; Lim, L.; Wong, C.W.; Chang, W.C.; Thomas, S.H.; Sanchez, J.F.; et al. Lenalidomide Enhances the Function of CS1 Chimeric Antigen Receptor-Redirected T Cells Against Multiple Myeloma. Clin. Cancer Res. 2018, 24, 106-119. [CrossRef] [PubMed]

6. Ruella, M.; Kenderian, S.S.; Shestova, O.; Fraietta, J.A.; Qayyum, S.; Zhang, Q.; Maus, M.V.; Liu, X.; Nunez-Cruz, S.; Klichinsky, M.; et al. The Addition of the BTK Inhibitor Ibrutinib to Anti-CD19 Chimeric Antigen Receptor T Cells (CART19) Improves Responses against Mantle Cell Lymphoma. Clin. Cancer Res. 2016, 22, 2684-2696. [CrossRef] [PubMed]

7. Otahal, P.; Prukova, D.; Kral, V.; Fabry, M.; Vockova, P.; Lateckova, L.; Trneny, M.; Klener, P. Lenalidomide enhances antitumor functions of chimeric antigen receptor modified T cells. Oncoimmunology 2016, 5, e1115940. [CrossRef] [PubMed]

8. Fowler, N.H.; Cheah, C.Y.; Gascoyne, R.D.; Gribben, J.; Neelapu, S.S.; Ghia, P.; Bollard, C.; Ansell, S.; Curran, M.; Wilson, W.H.; et al. Role of the tumor microenvironment in mature B-cell lymphoid malignancies. Haematologica 2016, 101, 531-540. [CrossRef]

9. Andersen, M.H. The targeting of immunosuppressive mechanisms in hematological malignancies. Leukemia 2014, 28, 1784-1792. [CrossRef]

10. Melero, I.; Berman, D.M.; Aznar, M.A.; Korman, A.J.; Perez Gracia, J.L.; Haanen, J. Evolving synergistic combinations of targeted immunotherapies to combat cancer. Nat. Rev. Cancer 2015, 15, 457-472. [CrossRef]

11. Halliwell, B. Oxidative stress and cancer: Have we moved forward? Biochem. J. 2007, 401, 1-11. [CrossRef] [PubMed]

12. Corzo, C.A.; Cotter, M.J.; Cheng, P.; Cheng, F.; Kusmartsev, S.; Sotomayor, E.; Padhya, T.; McCaffrey, T.V.; McCaffrey, J.C.; Gabrilovich, D.I. Mechanism regulating reactive oxygen species in tumor-induced myeloid-derived suppressor cells. J. Immunol. 2009, 182, 5693-5701. [CrossRef]

13. Schmielau, J.; Finn, O.J. Activated granulocytes and granulocyte-derived hydrogen peroxide are the underlying mechanism of suppression of t-cell function in advanced cancer patients. Cancer Res. 2001, 61, 4756-4760. 
14. Daum, S.; Chekhun, V.F.; Todor, I.N.; Lukianova, N.Y.; Shvets, Y.V.; Sellner, L.; Putzker, K.; Lewis, J.; Zenz, T.; de Graaf, I.A.; et al. Improved synthesis of N-benzylaminoferrocene-based prodrugs and evaluation of their toxicity and antileukemic activity. J. Med. Chem. 2015, 58, 2015-2024. [CrossRef] [PubMed]

15. Daum, S.; Reshetnikov, M.S.V.; Sisa, M.; Dumych, T.; Lootsik, M.D.; Bilyy, R.; Bila, E.; Janko, C.; Alexiou, C.; Herrmann, M.; et al. Lysosome-Targeting Amplifiers of Reactive Oxygen Species as Anticancer Prodrugs. Angew. Chem. Int. Ed. Engl. 2017, 56, 15545-15549. [CrossRef]

16. Marzenell, P.; Hagen, H.; Sellner, L.; Zenz, T.; Grinyte, R.; Pavlov, V.; Daum, S.; Mokhir, A. Aminoferrocene-based prodrugs and their effects on human normal and cancer cells as well as bacterial cells. J. Med. Chem. 2013, 56, 6935-6944. [CrossRef]

17. Doering, M.; Ba, L.A.; Lilienthal, N.; Nicco, C.; Scherer, C.; Abbas, M.; Zada, A.A.; Coriat, R.; Burkholz, T.; Wessjohann, L.; et al. Synthesis and selective anticancer activity of organochalcogen based redox catalysts. J. Med. Chem. 2010, 53, 6954-6963. [CrossRef] [PubMed]

18. Turtle, C.J.; Hay, K.A.; Hanafi, L.A.; Li, D.; Cherian, S.; Chen, X.; Wood, B.; Lozanski, A.; Byrd, J.C.; Heimfeld, S.; et al. Durable Molecular Remissions in Chronic Lymphocytic Leukemia Treated with CD19-Specific Chimeric Antigen Receptor-Modified T Cells After Failure of Ibrutinib. J. Clin. Oncol. 2017, 35, 3010-3020. [CrossRef] [PubMed]

19. Porter, D.L.; Levine, B.L.; Kalos, M.; Bagg, A.; June, C.H. Chimeric antigen receptor-modified T cells in chronic lymphoid leukemia. N. Engl. J. Med. 2011, 365, 725-733. [CrossRef]

20. Porter, D.L.; Hwang, W.T.; Frey, N.V.; Lacey, S.F.; Shaw, P.A.; Loren, A.W.; Bagg, A.; Marcucci, K.T.; Shen, A.; Gonzalez, V.; et al. Chimeric antigen receptor T cells persist and induce sustained remissions in relapsed refractory chronic lymphocytic leukemia. Sci. Transl. Med. 2015, 7, 303ra139. [CrossRef]

21. Schuster, S.J.; Bishop, M.R.; Tam, C.S.; Waller, E.K.; Borchmann, P.; McGuirk, J.P.; Jager, U.; Jaglowski, S.; Andreadis, C.; Westin, J.R.; et al. Tisagenlecleucel in Adult Relapsed or Refractory Diffuse Large B-Cell Lymphoma. N. Engl. J. Med. 2019, 380, 45-56. [CrossRef] [PubMed]

22. Neelapu, S.S.; Locke, F.L.; Bartlett, N.L.; Lekakis, L.J.; Miklos, D.B.; Jacobson, C.A.; Braunschweig, I.; Oluwole, O.O.; Siddiqi, T.; Lin, Y.; et al. Axicabtagene Ciloleucel CAR T-Cell Therapy in Refractory Large B-Cell Lymphoma. N. Engl. J. Med. 2017, 377, 2531-2544. [CrossRef] [PubMed]

23. Maude, S.L.; Laetsch, T.W.; Buechner, J.; Rives, S.; Boyer, M.; Bittencourt, H.; Bader, P.; Verneris, M.R.; Stefanski, H.E.; Myers, G.D.; et al. Tisagenlecleucel in Children and Young Adults with B-Cell Lymphoblastic Leukemia. N. Engl. J. Med. 2018, 378, 439-448. [CrossRef]

24. Fraietta, J.A.; Beckwith, K.A.; Patel, P.R.; Ruella, M.; Zheng, Z.; Barrett, D.M.; Lacey, S.F.; Melenhorst, J.J.; McGettigan, S.E.; Cook, D.R.; et al. Ibrutinib enhances chimeric antigen receptor T-cell engraftment and efficacy in leukemia. Blood 2016, 127, 1117-1127. [CrossRef] [PubMed]

25. Zhou, Y.; Hileman, E.O.; Plunkett, W.; Keating, M.J.; Huang, P. Free radical stress in chronic lymphocytic leukemia cells and its role in cellular sensitivity to ROS-generating anticancer agents. Blood 2003, 101, 4098-4104. [CrossRef]

26. Jitschin, R.; Hofmann, A.D.; Bruns, H.; Giessl, A.; Bricks, J.; Berger, J.; Saul, D.; Eckart, M.J.; Mackensen, A.; Mougiakakos, D. Mitochondrial metabolism contributes to oxidative stress and reveals therapeutic targets in chronic lymphocytic leukemia. Blood 2014, 123, 2663-2672. [CrossRef] [PubMed]

27. Wilson, W.R.; Hay, M.P. Targeting hypoxia in cancer therapy. Nat. Rev. Cancer 2011, 11, 393-410. [CrossRef]

28. Wuchter, P.; Saffrich, R.; Giselbrecht, S.; Nies, C.; Lorig, H.; Kolb, S.; Ho, A.D.; Gottwald, E. Microcavity arrays as an in vitro model system of the bone marrow niche for hematopoietic stem cells. Cell Tissue Res. 2016, 364, 573-584. [CrossRef] [PubMed]

29. Ligtenberg, M.A.; Mougiakakos, D.; Mukhopadhyay, M.; Witt, K.; Lladser, A.; Chmielewski, M.; Riet, T.; Abken, H.; Kiessling, R. Coexpressed Catalase Protects Chimeric Antigen Receptor-Redirected T Cells as well as Bystander Cells from Oxidative Stress-Induced Loss of Antitumor Activity. J. Immunol. 2016, 196, 759-766. [CrossRef]

30. Schubert, M.L.; Hoffmann, J.M.; Dreger, P.; Muller-Tidow, C.; Schmitt, M. Chimeric antigen receptor transduced T cells: Tuning up for the next generation. Int. J. Cancer 2018, 142, 1738-1747. [CrossRef]

31. Stock, S.; Ubelhart, R.; Schubert, M.L.; Fan, F.; He, B.; Hoffmann, J.M.; Wang, L.; Wang, S.; Gong, W.; Neuber, B.; et al. Idelalisib for optimized CD19-specific chimeric antigen receptor T cells in chronic lymphocytic leukemia patients. Int. J. Cancer 2019. [CrossRef] [PubMed] 
32. Stock, S.; Hoffmann, J.M.; Schubert, M.L.; Wang, L.; Wang, S.; Gong, W.; Neuber, B.; Gern, U.; Schmitt, A.; Muller-Tidow, C.; et al. Influence of Retronectin-Mediated T-Cell Activation on Expansion and Phenotype of CD19-Specific Chimeric Antigen Receptor T Cells. Hum. Gene Ther. 2018, 29, 1167-1182. [CrossRef] [PubMed]

33. Hoffmann, J.M.; Schubert, M.L.; Wang, L.; Huckelhoven, A.; Sellner, L.; Stock, S.; Schmitt, A.; Kleist, C.; Gern, U.; Loskog, A.; et al. Differences in Expansion Potential of Naive Chimeric Antigen Receptor T Cells from Healthy Donors and Untreated Chronic Lymphocytic Leukemia Patients. Front. Immunol. 2017, 8, 1956. [CrossRef] [PubMed]

(C) 2019 by the authors. Licensee MDPI, Basel, Switzerland. This article is an open access article distributed under the terms and conditions of the Creative Commons Attribution (CC BY) license (http://creativecommons.org/licenses/by/4.0/). 